\title{
Gentamicin Induced Hepatotoxicity: An approach of Hepatoprotecion by Garlic
}

\author{
R. Mishra ${ }^{1}$ and V. K. Shrivastava ${ }^{2}$ \\ ${ }^{1}$ Laboratory of Endocrinology, Department of Biosciences, Barkatullah University, Bhopal, 462026 (M.P.) India \\ ${ }^{2}$ Laboratory of Endocrinology, Department of Biosciences, Barkatullah University, Bhopal, 462026 (M.P.) India \\ *Corresponding Author: richa_richamishra@yahoo.co.in
}

Available online at: www.isroset.org

Received: 07/Dec/2018, Accepted: 21/Dec/2018, Online: 31/Dec?2018

\begin{abstract}
Gentamicin hepatotoxicity is a major clinical drawback. This investigation was performed to scrutinize the effect of garlic extract as a herbal antidote on liver toxicity after treatment with gentamicin in male albino rats. Gentamicin is a widely used anti-infective broad-spectrum antibiotic of aminoglycoside family. Side effects of gentamicin medication occur due to free radical formation. Garlic, the bulb of Allium sativum, is universally used as a spice and also known for its medicinal and antioxidant properties. Forty adult male albino rats, Rattus norvegicus were randomly classified into four groups of ten each. Group 1 received $0.9 \%$ normal saline orally per day and served as control while group 2 received gentamicin intramuscularly per day, however group 3 received both gentamicin intramuscularly per day and garlic extract orally per day, while group 4 received only garlic extract orally per day for 30 and 60 days respectively. Gentamicin caused various structural and functional changes in hepatic cell, increased glutamate pyruvate transaminase (GPT), glutamate oxaloacetate transaminase (GOT), acid phosphatase (ACP), alkaline phosphatase (ALP) and decreased total protein and creatinine level. Co-administration of garlic extract to rats ameliorates the gentamicin toxicity at some extent in hepatic cells as shown in the results of biochemical, enzymological and histopathological studies. Garlic extract was effective in recovering the level of hepatic enzymes, biochemical markers and histological alterations; hence, it may be concluded that garlic reduces the gentamicin hepatotoxicity in rats.
\end{abstract}

Keywords-Gentamicin; Hepatotoxicity; Garlic extract; Hepatoprotection; Male Rattus norvegicus.

\section{INTRODUCTION}

The liver is the major organ for drug metabolism and excretion in the body therefore it is a preferred target for drug toxicity. Drug-induced liver injury is a major clinical problem and cause of acute liver failure and transplantation [1]. Liver is exposed to several xenobiotics such as chemicals, toxins, drugs etc and susceptible to cirrhosis, acute chronic hepatitis and hepatitis [2]. Drug-induced liver injury mainly involves two mechanism of pathogenesis: adverse immune reactions and direct hepatotoxicity that affects biochemical functions of the cell [3]. It is initiated by the bioactivation of drugs to chemically reactive metabolites, which have the ability to interact with cellular macromolecules such as proteins, lipids and nucleic acids, leading to protein dysfunction, lipid peroxidation, DNA damage and oxidative stress [4]. U.S. Food and Drug Administration (FDA) have also removed some drugs from the pharmaceutical market because of drug-induced liver injury [5].

Aminoglycosides are a family of broad-spectrum antibiotics that exhibit bactericidal action and interrupt bacterial protein synthesis by binding to the A-site on the $16 \mathrm{~S}$ ribosomal RNA of the $30 \mathrm{~S}$ subunit [6,7]. This inhibit the formation of initiation complex with mRNA and thus inducing a misreading of the genetic code, which give rise to defective proteins that leads to cell death $[8,9]$. Some very important clinical features of aminoglycoside antibiotics are an excellent antibacterial profile against Gram-negative lifethreatening infections, low cost, synergism with the wallaffecting antibiotics (beta-lactams, glycopeptides), high bactericidal efficacy (concentration-dependent killing) and low level of resistance [10].

Gentamicin continues to be the aminoglycoside of choice for serious hospital-acquired infections caused by Enterobacteriaceae and Pseudomonas aeruginosa, but their use is limited due to their toxic nature $[11,12,13]$. Gentamicin is involved in the formation of free radicals [14]. Mechanism of gentamicin toxicity is based on the formation of cytotoxic metabolite [15,16]. Gentamicin is associated with hepatotoxicity, which causes irregular and condensed nuclear materials, organelles deteriorations and Poly (ADPribose) polymerase fragmentation and induce apoptosis in rat hepatic cells $[17,18]$. 
It is well documented that herbs are known to play a vital role in the management of various diseases including hepatic diseases. Popularity of herbal remedies is increasing and at least one quarter of patients with liver disease use herbal medicine. The World Health Organization (WHO) estimates that 80 percent of the population of some Asian and African countries presently uses herbal medicine for some aspect of primary health care. Some medicinal herbs have proven hepatoprotective potential [19]. Garlic (Allium sativum) has been recognized since ancient times not only as a flavoring agent for food but also for its medicinal properties. The consumption of traditional plants especially garlic has progressively increased worldwide because of their great effectiveness, fewer side effects and relatively low cost [20]. It has cardioprotective [21], anticarcinogenic [22], antimicrobial [23], antioxidant [24], anti-inflammatory [25], immunomodulatory [25] and hepatoprotective [26] properties. Garlic is a rich source of organosulfur compounds for example aliin, allicin, ajoene, allyl sulfide, Sallylcysteine, vinyl dithiines, S-allylmercaptocystein and others [27]. The garlic organosulfur components are mainly responsible for its antioxidant properties [28].

The target of the present study was to investigate the possible ameliorative role of garlic against the toxicity of gentamicin in male albino rats by observing the histopathological, biochemical and enzymological parameters.

\section{MeThODOLOGY}

\section{Materials and Method}

\section{Chemicals}

The gentamicin antibiotic injection was procured from (Lupigenta ${ }^{\circledR}$, Lupin Ltd, Mumbai, India, $30 \mathrm{ml}$ ) containing $80 \mathrm{mg} / 2 \mathrm{ml}$ for intramuscular and intravenous use. Crude garlic extract (Allium sativum) was obtained from commercially available capsule fills of garlic extract (Lasuna ${ }^{\circledR}$, Himalaya Drug Company, Bangalore, India, 60 capsules) containing $250 \mathrm{mg}$ of extract per capsules. The capsule fills were opened and dry garlic powder extract was dissolved in saline to prepare a concentration of $25 \mathrm{mg} / 0.1 \mathrm{ml}$ and administered through gavage to a rat at a dose of (250 $\mathrm{mg} / \mathrm{kg}$ body weight). All the reagents and chemicals were used of analytical grade.

\section{Experimental animals and treatment}

This experimental study was done after the approval of Institutional Animal Ethics Committee (IAEC) on the use of laboratory animals and animals were handled in accordance with the guidelines of the Committee for the purpose of Control and Supervision of Experiments on Animals (CPCSEA). The approval registration no:1885/GO/Re/S/16/CPCSEA/IAEC/BU/06 was given by IAEC.
The adult male albino rats (Rattus norvegicus) having weight of $110 \pm 10 \mathrm{gm}$ were used for this experiment. All animals were acclimatized two week prior to the commencement of the experiment to laboratory conditions i.e. at $24 \pm 2{ }^{\circ} \mathrm{C}$ temperature and light and dark cycle of 12 hours in the Animal House of Laboratory of Endocrinology, Department of Biosciences, Barkatullah University, Madhya Pradesh, India. Hygienic conditions were maintained with rice husk bedding in polypropylene cages. Animals were fed on standard rat feed and water ad libitum. Forty experimental animals were divided into four groups of ten each, which were as follows:

Group 1 $(n=10)$ : This group of animals were served as control, received balanced diet, water ad libitum and administration of $0.9 \%$ normal saline $(1 \mathrm{ml} / \mathrm{kg}$ body weight/day, orally) as vehicle for 30 and 60 days respectively.

Group 2(n=10): The animals of this group were received balanced diet, water ad libitum and exposed to gentamicin (37 mg/kg body weight/day, intramuscularly) for 30 and 60 days respectively.

Group 3(n=10): The animals of this group were received balanced diet, water ad libitum and exposed to gentamicin (37 $\mathrm{mg} / \mathrm{kg}$ body weight/day, intramuscularly) and supplemented with garlic extract $(250 \mathrm{mg} / \mathrm{kg}$ body weight/day, orally) though gavage for 30 and 60 days respectively.

Group 4(n=10): The animals of this group were received balanced diet, water ad libitum and supplemented with garlic extract $(250 \mathrm{mg} / \mathrm{kg}$ body weight/day, orally) only through gavage for 30 and 60 days respectively.

After the completion of different durations i.e. 30, and 60 days all animals of each group were sacrificed by cervical dislocation at different intervals i.e. $31^{\text {th }}$ and $61^{\text {th }}$ day of experiments and following parameters were done during the experimental investigation.

\section{Biochemical and enzymological analysis}

Every rat was sacrificed by cervical dislocation and liver was quickly dissected out, washed in $0.9 \%$ of normal saline thoroughly, cleared the adherent tissue debris, blotted dry and weighed. The tissues were then used to prepare homogenates and total protein, creatinine and some enzymes activity such as glutamate pyruvate transaminase (GPT), glutamate oxaloacetate transaminase (GOT), acid phosphatase (ACP) and alkaline phosphatase (ALP) were estimated.

Protein estimation was done by Follin-Phenol method [29], estimation of creatinine was done by Jaffe's method [30], estimation of GPT and GOT were done by adopting the methodology of Reitman and Frankel [31] and estimation of ALP and ACP were done by adopting the methodology of Bergmeyer and Bernt [32]. 


\section{Histological preparation}

A part of liver was collected from all the groups, fixed in Bouin's fluid, dehydrated in ascending grades of ethyl alcohol, cleared in xylene and mounted in molten paraffin wax. Fine micron sections of $5 \mu$ were cut by adopting microtomy, stained with Hematoxylin and Eosin [33] and these sections were observed for any structural changes under compound microscope and followed by microphotography using microphotography unit.

\section{Statistical analysis}

One way analysis of variance (ANOVA) was used to analyze the results through Sigma Tec software for comparison between different experimental rat groups. The results were expressed as means \pm SEM values and the values for $p<0.05$ were considered significant, $\mathrm{p}<0.01$ were considered more significant and the values $\mathrm{p}<0.001$ were considered as highly significant [34].

\section{RESUlTS AND DISCUSSION}

\section{RESULTS}

In the biochemical estimations, gentamicin exposed rats significantly lowered the hepatic protein and creatinine levels after 30 and 60 days in comparison to control group. However when the rats were supplemented with garlic extract along with gentamicin showed some ameliorative role in the hepatic protein and creatinine levels after 30 and 60 days in comparison to control group. While, rats supplemented with only garlic extract for 30 and 60 days showed normal levels of protein and creatinine in liver as shown in (Figure 1 and 2).

As per the enzymological activities, the hepatic enzymes level were modified when rats exposed to gentamicin and gentamicin + garlic extract for 30 and 60 days in comparison to control group. Glutamate pyruvate transaminase (GPT) and glutamate oxaloacetate transaminase (GOT) were significantly increased after 30 and 60 days exposure of gentamicin when compared with control. While, the supplementation of garlic extract along with gentamicin for 30 and 60 days showed recoveries and the rats supplemented with only garlic extract for 30 and 60 days showed normal levels of enzymes as compared to control as shown in (Figure 3 and 4). In continuation to this, the hepatic acid phosphatase (ACP) and alkaline phosphatase (ALP) levels were significantly increased after 30 and 60 days in gentamicin exposed group as compared to control group. While, rats supplemented with garlic extract along with gentamicin, ameliorative effects in the enzymatic reactions were noticed in comparison to control. However, rats supplemented with garlic extract only for 30 and 60 days showed normal levels enzyme activities similar to control group as shown in (Figure 5 and 6).
According to the histological observations, liver of rats of control group and garlic extract supplemented group for 30 and 60 days showed normal histoarchitecture of liver characterized by well defined and uniform spherical nuclei and large amount of cytoplasm (Figure 7 and 10). However, the rats exposed with the gentamicin for 30 and 60 days showed sever changes in hepatic cells characterized by degenerated nuclei, vacuolization and less amount of cytoplasmic materials as compared to control group (Figure 8 ). But, the rats supplemented with garlic extract along with gentamicin for 30 and 60 days showed ameliorative effects in their cellular structure in comparison to gentamicin exposed group (Figure 9).

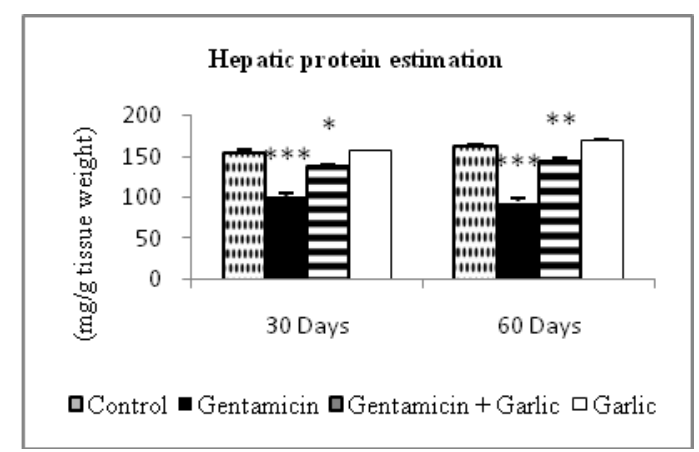

Figure 1: Histogram showing hepatic protein estimation

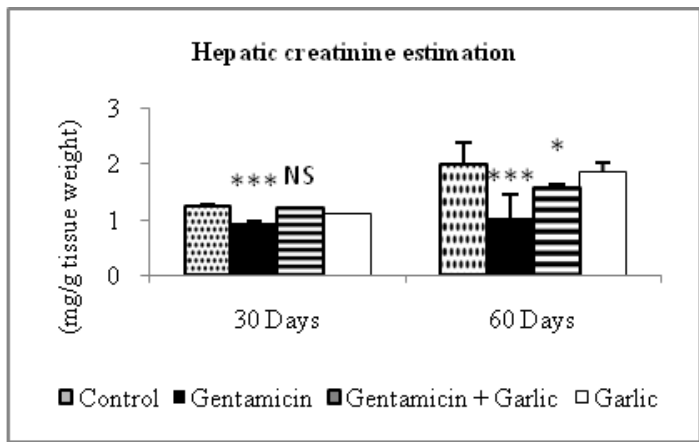

Figure 2: Histogram showing creatinine estimation

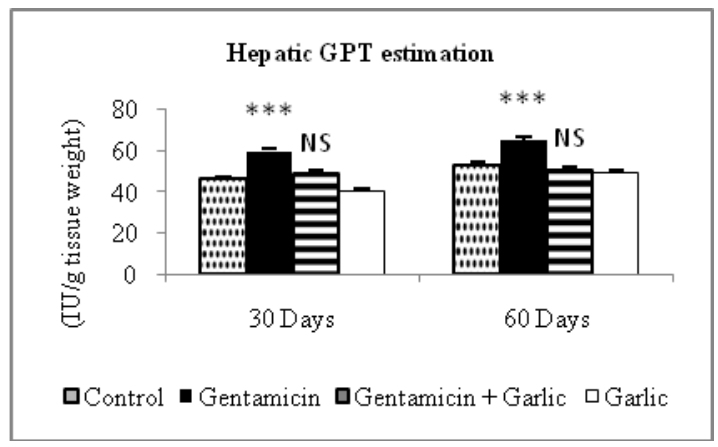

Figure 3: Histogram showing hepatic GPT estimation 


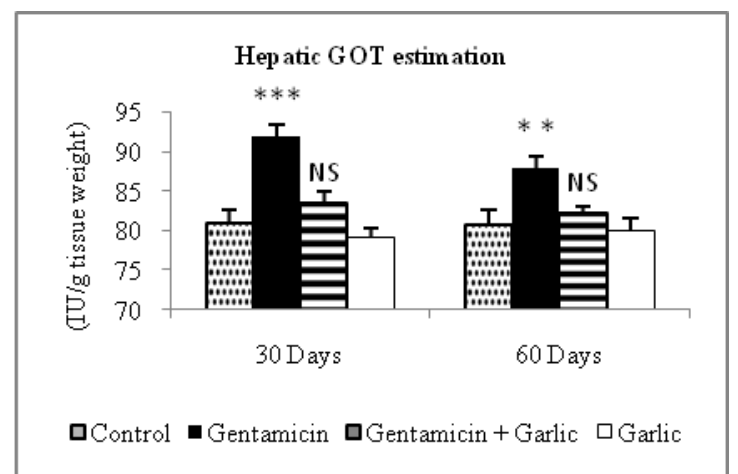

Figure 4: Histogram showing hepatic GOT estimation

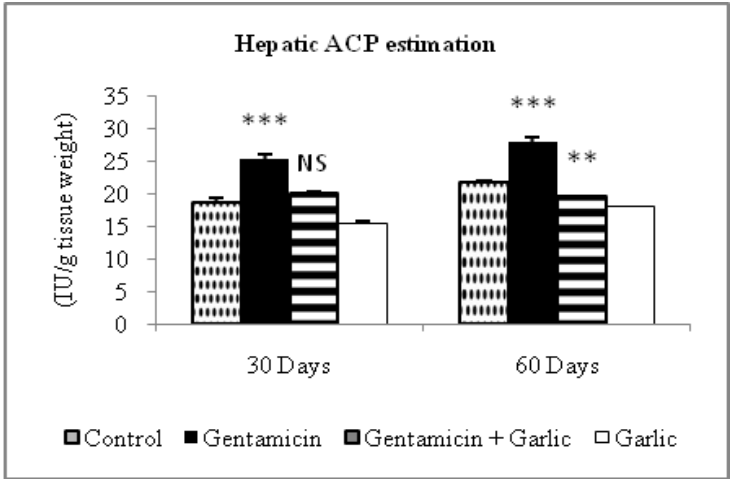

Figure 5: Histogram showing hepatic ACP estimation

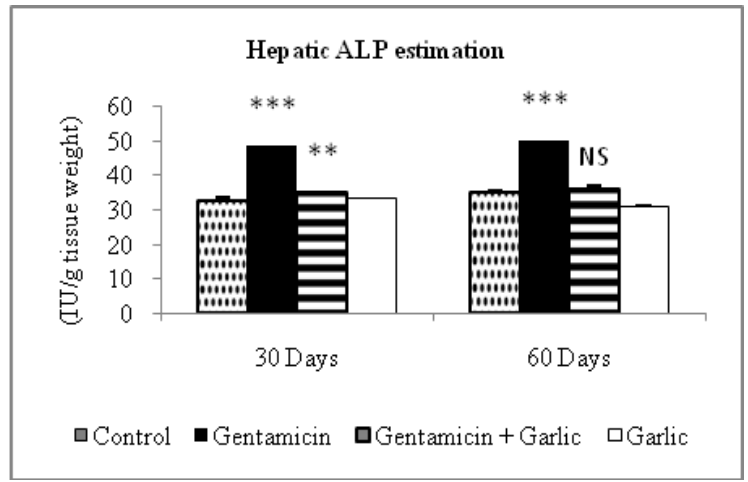

Figure 6: Histogram showing hepatic ALP estimation

Note: $(*$ Significant difference $(\mathrm{p}<0.05)$ from the control versus treated by one way ANOVA, **More significant difference $(\mathrm{p}<0.01)$ from the control versus treated by one way ANOVA, ***Highly significant difference $(p<0.001)$ from the control versus treated by one way ANOVA, ${ }^{\text {NS Non }}$ significant from the control versus treated by one way ANOVA)

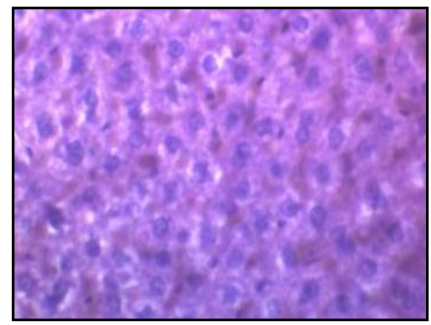

Figure 7: Histological section of control group

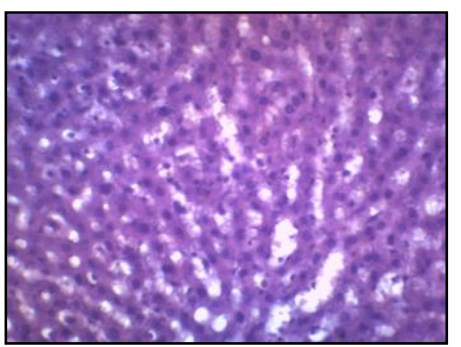

Figure 8: Histological section of Gentamicin induced hepatotoxicity group

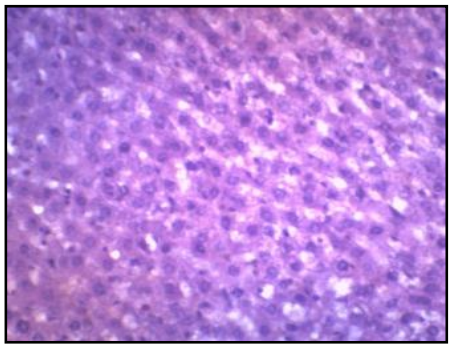

Figure 9: Histological section of Gentamicin+Garlic extract group

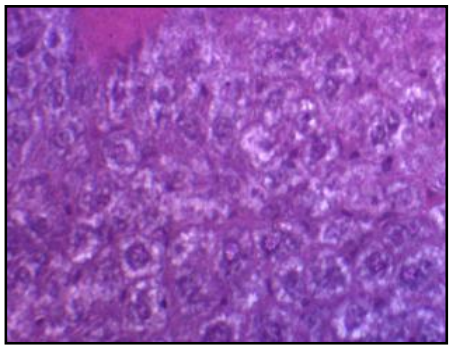

Figure 10: Histological section of Garlic extract group

\section{Discussion}

After 50 years of use, gentamicin continues to provide a mainstay in the therapy of serious Gram-negative infections because of a low price and high effectivity. Thus, gentamicin, while being "old" drugs, will continue to have impact on modern medicine as powerful antibiotic, experimental therapeutics and invaluable tool compound for drug discovery. Gentamicin is an aminoglycoside antibiotic commonly used in treating life-threatening gram-negative bacterial infections [35]. Gentamicin was first isolated from Micromonospora purpurea, gram-positive bacteria widely present in water and soil, and was identified to have potential in treating various gram-negative bacterial infections [36,37]. Several studies have demonstrated the toxicological effect of gentamicin in various organs. In spite of its therapeutic importance, a wide range of adverse effect has been demonstrated in patients and experimental animals. Gentamicin generates free oxygen radicals and it eventually leads to tissue injury such as nephrotoxicity and ototoxicity [38]. Not only these disorders but also it causes hepatotoxicity [39].

On the other side, it is well known fact that some traditional 
herbs act as remedy, which can alter the toxicological effect of gentamicin. It is evident that medicinal use of garlic is widespread and growing. It has been found that organosulfur compounds contained in garlic has significant antioxidant effects [40].

In this study, we have studied about the ameliorative role of garlic extract against the gentamicin induced hepatotoxicity in rats. Gentamicin administration produced a decrease in liver protein and creatinine while supplementation with only garlic extract showed normal level of protein and creatinine as compared to the control group. However, the coadministration of gentamicin and garlic extract showed recoveries in the level of liver protein and creatinine. Creatinine concentration is interrupted by various circumstances including aging, ethnicity, gender, protein consumption and most importantly acute and chronic liver disease. Creatinine is formed as a by-product in the process of creatine metabolism and creatine is secreted in the liver by three amino acids, glycine, arginineand methionine. In chronic liver failure, the serum creatinine concentration reduces because of $50 \%$ decrease in hepatic production of creatine [41]. Measurement of protein levels is used for the diagnosis of hepatic dysfunction [42]. Hepatocytes are responsible for synthesis of most of the serum proteins [43]. Protein loss in gentamicin toxicity might decrease the level of specific proteins and thereby disturb the rate of metabolic activities. General mechanism of action of gentamicin involves misreading in protein synthesis [44]. Gentamicin inhibits the action of protein synthetic machinery by binding to ribosomal proteins in microorganisms as well as in mammalian organelles and cell extracts [45]. In a study, the total protein levels of rats fed with gentamicin were significantly reduced which is a reflection of the hepatotoxicity and supplement of cinnamon extract is given as an antioxidant [46]. Decrease in protein level affects overall physiological function of animals. However, administration of garlic extract along with gentamicin caused significant amelioration of enzymatic levels, biochemical markers and histological observations. This suggested the protective effects of garlic extract. This is in accordance with the result of [47]. The non-significant decrease in the total protein levels in the lead treated group indicates the hepatoprotective effects of the garlic extract.

Gentamicin treatment causes significant increase in the activity of liver function markers as compared to control group indicating hepatic dysfunctions. A recent report suggested gentamicin generates reactive oxygen species, which could induce apoptosis in rat liver cells and finally leads to liver failure [17]. The side effect of gentamicin is creating hepatotoxicity $[48,49]$.

Hepatocytes contain large amounts of enzymes in liver and these enzymes are useful for the diagnosis of liver damage. The commonest enzymes employed as useful indicators of hepatocellular damage are the glutamate pyruvate transaminase (GPT), glutamate oxaloacetate transaminase (GOT), acid phosphatase (ACP) and alkaline phosphatase (ALP).

Liver enzyme activities such as GPT, GOT, ACP and ALP were increased after gentamicin administration. While these enzymes were lowered after supplement of garlic extract. However, further reductions were observed followed by coadministration of gentamicin and garlic extract. Increase in liver enzyme activities is roughly proportional to the extent of tissue damage [50].

The results from this study confirmed that gentamicin at a dose of $37 \mathrm{mg} / \mathrm{kg}$ body weight daily for 30 and 60 days produces significant hepatotoxicity as evidenced by increase in the level of GPT, GOT, ACP, ALP and decrease in the values of protein and creatinine. The observed higher increase in the level of GOT over GPT may be due to a leakage of cytoplasmic enzymes into circulation as a result of inflammation of the liver cells. Elevations of these enzymes in experimental animals exposed to gentamicin were also reported by [51]. The cumulative oxidative damage is likely one of the mechanisms producing the hepatotoxic effects of gentamicin administration in this study. Liver histopathology served as the most important tool for identifying and characterizing liver injury.

\section{CONCLUSION AND Future SCOPE}

This investigation clearly indicates the importance garlic extract in the control of hepatic dysfunctions. Garlic extract was effective in recovering the level of hepatic enzymes, biochemical markers and histological alterations; hence it decreases hepatotoxicity in rats. According to the final outcome, it is suggested that intake of garlic with gentamicin might be healthy in males who prescribe gentamicin to cure infections.

\section{ACKNOWLEDGMENT}

I am extremely thankful to Department of Biotechnology, New Delhi for providing fellowship as research assistance under the scheme DBT-IPLS-BU.

\section{REFERENCES}

[1] Russmann S, Kullak-Ublick GA, Grattagliano I. Current concepts of mechanisms in drug-induced hepatotoxicity. Current medicinal chemistry. 2009 Aug 1;16(23):3041-53.

[2] Mukazayire MJ, Allaeys V, Calderon PB, Stévigny C, Bigendako MJ, Duez P. Evaluation of the hepatotoxic and hepatoprotective effect of Rwandese herbal drugs on in vivo (guinea pigs barbiturate-induced sleeping time) and in vitro (rat precision-cut liver slices, PCLS) models. Experimental and toxicologic pathology. 2010 May 1;62(3):289-99.

[3] Kaplowitz N. Drug-induced liver injury. Clinical Infectious Diseases. 2004 Mar 1;38(Supplement_2):S44-8. 
[4] Holt MP, Ju C. Mechanisms of drug-induced liver injury. The AAPS journal. 2006 Mar 1;8(1):E48-54.

[5] Lee WM. Drug-induced hepatotoxicity. New England Journal of Medicine. 2003 Jul 31;349(5):474-85.

[6] Hermann T. Aminoglycoside antibiotics: old drugs and new therapeutic approaches. Cellular and molecular life sciences. 2007 Jul 1;64(14):1841-52.

[7] Krause KM, Serio AW, Kane TR, Connolly LE. Aminoglycosides: an overview. Cold Spring Harbor perspectives in medicine. 2016 Jun 1;6(6):a027029.

[8] Davies J, Davis BD. Misreading of Ribonucleic Acid Code Words Induced by Aminoglycoside Antibiotics THE EFFECT OF DRUG CONCENTRATION. Journal of Biological Chemistry. 1968 Jun 25;243(12):3312-6.

[9] Davis BD, Chen LL, Tai PC. Misread protein creates membrane channels: an essential step in the bactericidal action of aminoglycosides. Proceedings of the National Academy of Sciences. 1986 Aug 1;83(16):6164-8.

[10] Begg EJ, Barclay ML, Duffull SB. A suggested approach to once- daily aminoglycoside dosing.British journal of clinical pharmacology. 1995 Jun 1;39(6):605-9.

[11] Kahlmeter G, Dahlager JI. Aminoglycoside toxicity-a review of clinical studies published between 1975 and 1982. Journal of Antimicrobial chemotherapy. 1984 Jan 1;13(suppl_A):9-22.

[12] EDSON RS, TERRELL CL. The aminoglycosides. InMayo Clinic Proceedings 1991 Nov 1 Vol. 66, No. 11, pp. 1158-1164. Elsevier.

[13] Edson RS, Terrell CL. The aminoglycosides. InMayo Clinic Proceedings 1999 May 1 Vol. 74, No. 5, pp. 519-528. Elsevier.

[14] Priuska EM, Schacht J. Formation of free radicals by gentamicin and iron and evidence for an iron/gentamicin complex. Biochemical pharmacology. 1995 Nov 27;50(11):1749-52.

[15] Huang MY, Schacht J. Formation of a cytotoxic metabolite from gentamicin by liver.1990.

[16] Crann SA, Huang MY, McLaren JD, Schacht J. Formation of a toxic metabolite from gentamicin by a hepatic cytosolic fraction.

[17] Alarifi SA, Alkahtani S, Al-Doaiss AA. Detection of apoptotsis induced by gentamicin in rat hepatocytes. International Journal of Zoological Research. 2009 Jan 1;5(4):161-70.

[18] Alkhatani S, Alarifi SA and Al-Doaiss A. Apoptotsis pathways induced by gentamicin in rat hepatocytes. In Orlando International Academic Conference. 2012 vol:1, pp. 265-272.

[19] Seif HS. Physiological changes due to hepatotoxicity and the protective role of some medicinal plants.Beni-suef university journal of basic and applied sciences. 2016 Jun 1;5(2):134-46.

[20] Suleria HA, Butt MS, Khalid N, Sultan S, Raza A, Aleem M, Abbas M. Garlic (Allium sativum): diet based therapy of 21st century-a review. Asian Pacific Journal of Tropical Disease. 2015 Apr 1;5(4):271-8.

[21] Khatua TN, Adela R, Baneriee SK. Garlic and cardioprotection: insights into the molecular mechanisms. Canadian journal of physiology and pharmacology. 2013 Mar 6;91(6):448-58.

[22] Khanum F, Anilakumar KR, Viswanathan KR. Anticarcinogenic properties of garlic: a review. Critical reviews in food science and nutrition. 2004 Nov 1;44(6):479-88.

[23] Ankri S, Mirelman D. Antimicrobial properties of allicin from garlic. Microbes and infection. 1999 Feb 1;1(2):125-9.

[24] Chung LY. The antioxidant properties of garlic compounds: allylcysteine, alliin, allicin, and allyl disulfide. Journal of medicinal food. 2006 Jun 1;9(2):205-13.

[25] Schafer G, H Kaschula C. The immunomodulation and antiinflammatory effects of garlic organosulfur compounds in cancer chemoprevention. Anti-Cancer Agents in Medicinal Chemistry (Formerly Current Medicinal Chemistry-Anti-Cancer Agents). 2014 Feb 1;14(2):233-40.
[26] Bayan L, Koulivand PH, Gorji A. Garlic: a review of potential therapeutic effects. Avicenna journal of phytomedicine. 2014 Jan;4(1): 1 .

[27] Omar SH, Al-Wabel NA. Organosulfur compounds and possible mechanism of garlic in cancer.Saudi Pharmaceutical Journal. 2010 Jan 1;18(1):51-8.

[28] Vazquez-Prieto MA, Rodriguez Lanzi C, Lembo C, Galmarini CR, Miatello RM. Garlic and onion attenuates vascular inflammation and oxidative stress in fructose-fed rats. Journal of nutrition and metabolism. 2011 Aug 25;2011.

[29] Lowry OH, Rosebrough NJ, Farr AL, Randall RJ. Protein measurement with the Folin phenol reagent.Journal of biological chemistry. 1951 Nov 1;193(1):265-75.

[30] Toro G and Ackermann P. Quantitative determination of creatinine orheparinzed plasma urine by colorimetric kinetic method.Practical clinical chemistry $1^{\text {st }}$ ed., Little Brown and Company, Boston.1975 pp237-238.

[31] Reitman S, Frankel S. A colorimetric method for the determination of serum glutamicoxalacetic and glutamic pyruvic transaminases. American journal of clinical pathology. $1957 \mathrm{Jul}$ 1;28(1):56-63.

[32] Bergmeyer HU and Bernt E. 1963, In: Methods of enzymatic analysis, edited by HU Bergmeyer, Academic Press, Weimheim, NY and London, 837.

[33] Ehrlich P. 1886, Fragekasten Zeitschnft Fur Wissenschaflliche Mikroskopic und Fur Mikroskopische Technik, 3, 150.

[34] Tukey JW. Comparing individual means in the analysis of variance. Biometrics. 1949 June 1:99-114.

[35] Ali BH. Gentamicin nephrotoxicity in humans and animals: some recent research. General Pharmacology: The Vascular System. 1995 Nov 1;26(7):1477-87.

[36] Rosselet JP, Marquez J, Meseck E, Murawski A, Hamdan A Joyner C, Schmidt R, Migliore D, Herzog HL. ISOLATION, PURIFICATION, AND CHARACTERIZATION OF GENTAMICIN. Antimicrobial agents and chemotherapy. 1963;161:14.

[37] Weinstein MJ, Luedemann GM, Oden EM, Wagman GH, Rosselet JP, Marquez JA, Coniglio CT, Charney W, Herzog HL, Black J. Gentamicin, 1 a new antibiotic complex from Micromonospora. Journal of medicinal chemistry. 1963 Jul;6(4):463-4.

[38] Bekheet SH, Awadalla EA, Salman MM, Hassan MK. Prevention of hepatic and renal toxicity with bradykinin potentiating factor (BPF) isolated from Egyptian scorpion venom (Buthusoccitanus) in gentamicin treated rats. Tissue and Cell. 2013 Apr 1;45(2):8994.

[39] Arjinajarn P, Chueakula N, Pongchaidecha A, Jaikumkao K, Chatsudthipong V, Mahatheeranont S, Norkaew O, Chattipakorn N, Lungkaphin A. Anthocyanin-rich Riceberry bran extract attenuates gentamicin-induced hepatotoxicity by reducing oxidative stress, inflammation and apoptosis in rats. Biomedicine \& Pharmacotherapy. 2017 Aug 1;92:412-20.

[40] Banerjee SK, Maulik M, Manchanda SC, Dinda AK, Das TK, Maulik SK. Garlic-induced alteration in rat liver and kidney morphology and associated changes in endogenous antioxidant status.Food and Chemical Toxicology. 2001 Aug 1;39(8):793-7.

[41] Slack A, Yeoman A, Wendon J. Renal dysfunction in chronic liver disease. Critical care. 2010 Apr;14(2):214.

[42] Hayden K, van Heyningen C. Measurement of total protein is a useful inclusion in liver function test profiles. Clinical chemistry. 2001 Apr 1;47(4):793-4.

[43] Thapa BR, Walia A. Liver function tests and their interpretation. The Indian Journal of Pediatrics. 2007 Jul 1;74(7):663-71.

[44] Tai PC, Davis BD.Triphasic concentration effects of gentamicin on activity and misreading in protein synthesis. Biochemistry. 1979 Jan;18(1):193-8. 
[45] Schwarze PE, Seglen PO. Effects of antibiotics on protein synthesis and degradation in primary cultures of rat hepatocytes.In vitro. 1981 Jan 1;17(1):71-6.

[46] Mahmood NA, Haleh MO, Mohammad PO, Mohsen FA, Hossein KJ. Pathological changes of gentamicin in liver tissue and antioxidant property of Cinnamon extract on Wistar rats. Biomed Pharmacol J. 2014;7(1):341-7.

[47] Sharma A, Sharma V, Kansal L. Amelioration of lead-induced hepatotoxicity by Alliumsativum extracts in Swiss albino mice. Libyan journal of Medicine. 2010 Jan 1;5(1):4621.

[48] Stojiljkovic N and Stoiljkovic M. Micromorphological characteristics of the liver and biochemical analyses in the blood of rats treated by gentamicinand verapamil. Actamedica Medianae.2006a, 45(2):5-9.

[49] Stojiljkovic N and Stoiljkovic M. Micromorphological and histochemical characteristics of a rat's liver treated with gentamicin. Acta medica Medianae.2006b, 45(3):24-28.

[50] Graw A, Cowan RA, O'Reilly DS, Stevant MJ, Stephard J. Clinical biochemistry-an illustrated color text. Is ted. New York: Churchill Livingstone. 1999:51-3.

[51] Khan MR, Badar I, Siddiquah A. Prevention of hepatorenal toxicity with Sonchusasper in gentamicin treated rats. BMC complementary and alternative medicine. 2011 Dec;11(1):113.

\section{AUTHORS PROFILE}

Prof Vinoy K. Shrivastava is currently working as Head of the Department of Biosciences of Barkatullah University Bhopal, Madhya Pradesh, India.

Richa Mishra is working as Reasearch Scholar under the supervision of Prof Vinoy K. Shrivastava in the laboratory of Endocrinology of Department of Biosciences of Barkatullah University Bhopal, Madhya Pradesh, India. 